\title{
Strategies Designed To Promote Active Learning And Student Satisfaction
}

\author{
Sandra A. Sessa, (E-mail: sessas@georgian.edu), Georgian Court University
}

\begin{abstract}
Four strategies designed to promote active learning and student satisfaction were employed with two classes of undergraduate students, one day and one evening, in a course in adolescent development. They included the use of small group collaborative testing; face-to-face interviews with adolescents and oral presentations of the results; naturalistic field observations with reports and discussion; and PowerPoint slide presentations with handouts. The students anonymously rated each of the strategies using a likert-type scale at the end of the semester. The evaluations were very positive with $89 \%$ to $97 \%$ of the students rating the strategies as "liked it very much" or "liked it" for all of the strategies. The average grade achieved in both classes was a " $B$ ". Means for the day class were compared to the evening class and no significant differences were found, suggesting similar positive ratings by both classes. Findings add support to the literature regarding student preferences for the use of active learning methods, involvement in cooperative learning activities, and collaborative test taking compared to lectures "straight from the podium" and individual testing.
\end{abstract}

\section{INTRODUCTION}

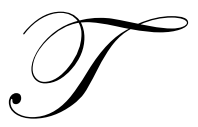

he task of the academic psychologist in today's university is a challenging one. We are charged with preparing students in our competitive collegiate learning world for positions in perhaps even more competitive job markets and graduate programs. Today, it is simply not enough to expect our charges to be passive recipients of verbal knowledge from "a mouth at a podium". Traditional methods often fall short in terms of keeping students' attention as well as promoting long-term retention of information (Thompson, Vermette \& Wisniewski, 2004). Meyers and Jones (1993) reviewed our traditional teaching practices in higher education and found that they have often "... reflected an authoritarian, detached, and competitive style that leaves little room for the views of women and other cultures." (p.8) Perhaps that approach had merit in American education in previous decades, but more now than ever before, our student population is changing. Adult learners, both women and men, often from diverse cultures are now more and more commonly our students (National Center for Education Statistics, 1992, cited in Meyers \& Jones, 1993, p.7). These individuals are far from "empty vessels" when they enter our educational institutions. They have life experiences, ideas, and perhaps different learning needs than our traditional students of the past. Another change is apparent. Many more of our students are first generation college students. Pascarella, Pierson, Wolniak and Terenzini (2004) reflect on the growing numbers of learners having neither parent with educational experience beyond high school; perhaps as much as one third of our first time freshmen.

We can no longer expect even our traditional students to spend four or five years in passive and individual learning roles without being alert to these changes. In addition, we must take into account the demands of their future work, which will require active problem solving, decision-making, collaborative work, and team efforts.

Many approaches have been used to enhance and improve the learning process. For instance, cognitive psychologists have long asserted that for new information to remain with us, it must connect with other similar information held in memory. One active way of achieving this is to tell or teach another person about the material (Springer, Stanne \& Donovan, 1999). We have seen evidence for decades that teaching methods that produce active engagement enhance learning (Fontes \& Piercy, 2000). Connor-Greene (2000) speaks specifically about the 
importance of assigning tasks to students that engage them actively in the learning process. This pedagogy for active learning is based on two underlying assumptions; the notion that learning is by its very nature, an active process; and that different people learn in different ways (Meyers \& Jones, 1993). These two assumptions have often been devalued in American higher education where the "expert gives and the learner receives". Active learning promotes a much more dynamic facilitation of the learning process.

It is quite possible that active learning also enables the student to retain what is learned for longer periods as well as be able to use what is learned. Halpern and Hakel (2003) elegantly delineate cognitive principles that promote long-term learning. If we want our students to truly own the materials we know they need to master, and be able to use them beyond the "test at the end of the term", we need to ask them to learn the materials in varied ways as well as to retrieve and use the information in multiple environments. In a summary of the principles, Halpern (2004) includes in her list of ways to promote long-term transfer of learning "...varying the conditions at learning, actively engaging attention, and recognizing that the learner's activity determines what is learned" (p.4). She too reminds us that the work culture of today is quite different from that of the past.

Our current college and university graduates are being required to behave in concert with those culture differences. The work world of the "rugged individualist" is giving way to the use of more and more work groups, collaborative models, and cooperative decision-making. Our students need to be able to function comfortably in these group situations.

The use of group testing has been explored. Researchers exploring the benefits of collaborative group testing state, "After graduation, most work in business, research and government is done in teams, and preparing students to appreciate the value of the social interaction and negotiations that make teams work effectively is vital for their future and that of our nation" (Zimbardo, Butler \& Wolfe in Smith, 2003, p.18). This model of test taking encourages shared responsibility and reduces anxiety in the test-taking process leading to increased comfort and better performance as well as promoting team work. When working in groups in a non-threatening environment, it is more likely that learning will occur. This more collaborative format may be particularly helpful to women and underrepresented groups providing more of an opportunity to be heard (Springer et al., 1999). Hence, group testing can provide not only a measure of information gained, but also an opportunity for active peer teaching, collaborative learning, and problem solving to take place providing a far richer experience than traditional individual test taking.

For this study four strategies were used in a course in Adolescent Development. The purpose of these strategies was to enhance both the learning of information and student satisfaction with the course. They included: 1) taking tests in a small group/partner format. Student test performance is said to be enhanced and anxiety reduced using this collaborative method (Zimbardo, Butler \& Wolfe, 2003). It can also be considered a type of cooperative learning which refers to "... any teaching method in which students teach to and learn from each other to reach a common goal" (Thompson et al., 2004, p.134); 2) conducting structured face-to-face interviews (see Appendix A) with adolescents and reporting the results to the class in the form of an oral presentation. This approach was used as a way to actively engage the students in their learning as well as to re-represent information gathered in one way (interviews) and present it in a different format (oral presentation); 3) conducting a naturalistic field observation, writing field notes, and then creating a report connecting various issues central to adolescent development that had been read about in their text book as well as discussed during class time. This assignment gave the students exposure to qualitative data collection and assisted them in seeing the difference between observation and inference (Fontes \& Piercy, 2000); 4) PowerPoint presentations and handouts. These presentations allowed for the main content points of a lecture or discussion to be presented visually while simultaneously being described verbally. Handouts of the slides with a lined section for notes were distributed before the presentation began.

\section{Method}

During the spring 2003 semester two sections of a course in adolescent development participated in the study. The students were all in attendance at a small private, predominantly female, college in the Northeast. One section of students $(\mathrm{n}=25,24$ female, 1 male) attended the evening class and one section of students $(\mathrm{n}=27$ women) attended the day class. Both sections were taught by the same instructor adding to consistency of the 
learning experience. At the end of the semester the students were asked to anonymously complete a likert-type questionnaire regarding the four methods used. (See Appendix B) They were also asked to write additional comments on the form addressing their opinions of the approaches overall.

\section{Partner/Group Tests}

The students in each class were offered the opportunity to take each of the four tests in a small group, usually in a trio, or to take the test alone. Only one student chose to take the tests alone (a day student). The questionnaire stated: "You have had the opportunity to take tests in a group/partner format. Please rate your experience with this format". The choices were the following: a-liked it very much; b-liked it; c-liked it a little; ddid not like it; e-did not like it at all. For calculation purposes, the value of an "a" response was 4; "b" was 3; "c" was 2 ; "d" was 1 ; and "e" 0 .

\section{Face-to-Face Interviews}

The students used a structured interview format (see appendix A) that had been created collaboratively by students and the researcher in another adolescent development class several years earlier. Signed permission from parents of minors was obtained prior to the interviews. The students interviewed the adolescents face-to-face and then made oral presentations of their findings to the class. The class was also given the opportunity to ask questions about the interview. At times, discussions ensued regarding the similarities and differences between the course readings and the answers given in the face-to-face interviews as well as the differences among the interviewee responses. At the end of the course, using the same likert-type format, the students responded to the following statement regarding the interview: "You conducted a face-to-face interview with an adolescent. Please indicate your opinion about the experience below".

\section{Naturalistic Observations}

The students were given specific directions for completing the field observation (see Appendix C). They were instructed about how to complete the observation and formulate a report linking their findings to information they had read and learned about in class. At the end of the course, using the same likert-type scale, the students responded to the following statement: "You conducted a naturalistic observation of an adolescent, couple, or group. Please rate that experience below."

\section{PowerPoint Presentations}

During the course of the semester the students were shown PowerPoint slide presentations with handouts for notes. At the end of the course the students were asked to respond to the following using the likert-type format: "Please state your opinion of the PowerPoint presentations and handouts".

\section{Results}

The total number of participants in the study was $52(\mathrm{~N}=52)$. This number represents the combination of day plus evening class participants. Twenty-seven students participated in the day class $(n=27)$ except for the field observations. Here the $\mathrm{n}$ was 26 due to one student not responding to that question. Twenty-five students participated in the evening class $(\mathrm{n}=25)$ except for the testing question where one participant answered " $\mathrm{b}$ and $\mathrm{c}$ " so the response was excluded from the calculations.

The means and standard deviations were calculated for each of the two classes for each of the approaches used and are displayed in Table 1 below. In addition, the "a" "liked it very much", and "b" "liked it", responses were combined and converted to percents of student responses and displayed in Table 2 below. Lastly, a comparison of the means for the day class compared to the evening class is displayed in Table 3 below. 
The range of possible mean scores was 0 to 4 . The results of the partner/group tests showed a mean of 3.77 with a standard deviation of .51 for day students and a mean of 3.66 with a standard deviation of .76 for the evening class. The results of the interview data showed a mean of 3.26 with a standard deviation of .65 for the day students and a mean of 3.44 and standard deviation of .71 for the evening class. The results of the naturalistic observation data showed a mean of 3.23 with a standard deviation of .65 for the day class and a mean of 3.44 with a standard deviation of .65 for the evening class.

The results of the PowerPoint data showed a mean of 3.80 with a standard deviation of .48 for the day class and a mean of 3.68 with a standard deviation of .85 for the evening class.

Table 1: Means and Standard Deviations on a 0-4 scale for each technique Group Statistics

\begin{tabular}{|l|c|c|c|c|c|}
\hline & Class & N & Mean & $\begin{array}{c}\text { Std. } \\
\text { Deviation }\end{array}$ & $\begin{array}{c}\text { Std. Error } \\
\text { Mean }\end{array}$ \\
\hline group tests & Day & 27 & 3.7778 & .5064 & $9.745 \mathrm{E}-02$ \\
& Eve & 24 & 3.6667 & .7614 & .1554 \\
\hline Interviews & Day & 27 & 3.2593 & .6559 & .1262 \\
& Eve & 25 & 3.4400 & .7118 & .1424 \\
\hline field & Day & 26 & 3.2308 & .6516 & .1278 \\
observations & Eve & 25 & 3.4400 & .6506 & .1301 \\
\hline \multirow{3}{*}{ powerpoints } & Day & 27 & 3.8148 & .4833 & $9.302 \mathrm{E}-02$ \\
& Eve & 25 & 3.6800 & .8524 & .1705 \\
\hline
\end{tabular}

The total of "a" "liked it very much", and "b" "liked it" responses combined for the day class indicated that $96 \%$ of the day students reported either "a" or "b" responses. The total of "a" and "b" responses for the evening class was $92 \%$. Combining day and evening responses yielded a total of $94 \%$ of all the students responding with either "liked it very much" or "liked it" with regard to partner/group tests.

The total of "a" "liked it very much" or "b" "liked it" responses for the day class was $89 \%$. The total for the evening class was $96 \%$ with the overall being $92 \%$ of all the students either liking very much or liking the interview techniques employed.

The percents of students responding "a" "liked it very much" or "b" "liked it" in the day class was $89 \%$ and $92 \%$ for the evening class. A combined result of $90 \%$ of the students reported either liking very much or liking the naturalistic field observations and reports.

The percent of students responding either "a" "liked it very much" or "b" "liked it" was $97 \%$ for the day class and $96 \%$ for the evening class. The overall percentage of students, day and evening, either liking very much or liking, the PowerPoint presentations and handouts was $96.5 \%$.

Table 2: Frequencies of "a" liked it very much and "b" "liked it" responses expressed in percents

\begin{tabular}{|l|c|c|c|c|c|}
\hline & Class & $\mathbf{n}$ & $\mathbf{a}+\mathbf{b}$ responses & a + b responses in \% & a+b day +eve in \% \\
\hline group tests & Day & 27 & 26 & $96 \%$ & \\
\hline & Eve & 24 & 22 & $92 \%$ & $94 \%$ \\
\hline Interviews & Day & 27 & 24 & $89 \%$ & $92 \%$ \\
\hline & Eve & 25 & 24 & $96 \%$ & \\
\hline observations & Day & 26 & 23 & $89 \%$ & $90 \%$ \\
\hline & Eve & 25 & 23 & $92 \%$ & $96.2 \%$ \\
\hline powerpoints & Day & 27 & 26 & $97 \%$ & $96 \%$ \\
\hline
\end{tabular}


The above table indicates very positive responses to all of the strategies employed. The percents indicate that overall, between $89 \%$ and $97 \%$ of all of the students either "liked very much" or "liked" each of the techniques employed in this study. These results appeared to be consistent across both day and evening classes.

An independent-samples $t$ test was conducted to evaluate whether there was a difference in the ratings of the day class compared to those of the evening class for each of the strategies. With respect to the group testing, there were no significant differences $t(49)=.620, p=.538$, between the means for the day class compared to the evening class. With respect to the interviews, there were no significant differences between the day and evening classes $t(50)=-.953, p=.345$. In terms of the field observations there were no significant differences between the day and evening classes, $t(49)=-1.147, p=.257$. Lastly, in terms of the PowerPoint presentation and handouts there were no significant differences between the classes $t(50)=.708, p=.482$. The positive student responses to all of the four methods were quite similar for both groups.

Table 3: Independent Samples Test

\begin{tabular}{|c|c|c|c|c|c|c|c|c|}
\hline & \multicolumn{7}{|c|}{ Levene's Test for Equality of Variances } \\
\hline & & $\mathrm{F}$ & Sig. & $\mathrm{T}$ & $\mathrm{df}$ & Sig. (2-tailed) & $\begin{array}{c}\text { Mean } \\
\text { Difference }\end{array}$ & $\begin{array}{l}\text { Std. Error } \\
\text { Difference }\end{array}$ \\
\hline group tests & $\begin{array}{l}\text { Equal variances assumed } \\
\text { Equal variances not assumed }\end{array}$ & 1.748 & .192 & $\begin{array}{l}.620 \\
.606\end{array}$ & $\begin{array}{c}49 \\
39.271\end{array}$ & $\begin{array}{l}.538 \\
.548\end{array}$ & $\begin{array}{l}.1111 \\
.1111\end{array}$ & $\begin{array}{l}.1792 \\
.1834\end{array}$ \\
\hline Interviews & $\begin{array}{l}\text { Equal variances assumed } \\
\text { Equal variances not assumed }\end{array}$ & .109 & .742 & $\begin{array}{l}-.953 \\
-.950\end{array}$ & $\begin{array}{c}50 \\
48.754\end{array}$ & $\begin{array}{l}.345 \\
.347\end{array}$ & $\begin{array}{l}-.1807 \\
-.1807\end{array}$ & $\begin{array}{l}.1897 \\
.1903\end{array}$ \\
\hline $\begin{array}{l}\text { Field } \\
\text { observations }\end{array}$ & $\begin{array}{l}\text { Equal variances assumed } \\
\text { Equal variances not assumed }\end{array}$ & .315 & .577 & $\begin{array}{l}-1.147 \\
-1.147\end{array}$ & $\begin{array}{c}49 \\
48.927\end{array}$ & $\begin{array}{l}.257 \\
.257\end{array}$ & $\begin{array}{l}-.2092 \\
-.2092\end{array}$ & $\begin{array}{l}.1824 \\
.1824\end{array}$ \\
\hline Power points & $\begin{array}{l}\text { Equal variances assumed } \\
\text { Equal variances not assumed }\end{array}$ & 1.756 & .191 & $\begin{array}{l}.708 \\
.694\end{array}$ & $\begin{array}{c}50 \\
37.359 \\
\end{array}$ & $\begin{array}{l}.482 \\
.492 \\
\end{array}$ & $\begin{array}{l}.1348 \\
.1348\end{array}$ & $\begin{array}{l}.1903 \\
.1942\end{array}$ \\
\hline
\end{tabular}

Table 4: Representative Written Comments from Students*

- $\quad$ Very helpful - I enjoyed the class very much and learned a lot.
- $\quad$ I found it interesting and kind of fun!
-
-
-
-
-
-
Ineye more interest and allowed for more class participation. Enjoyed going to class and took a lot of stress away.
Made it more interesting and showed us what we were learning in the actual environment.
I really enjoyed the class. These approaches made it easier to understand and learn the material.
I think Dr. Sessa's way of teaching has taught me a lot. I never learn anything from straight lectures from the
podium. The group testing made me feel more relaxed unlike individual, which make me nervous.
The different approaches made the class more enjoyable and unique from my other "lecture from the podium
classes". I highly enjoyed your class and learned a lot! Thank you.
Very good, helped me pay attention and follow along and comprehend.
It made the class more enjoyable having a variety of teaching approaches keeps students interested and willing to
- $\quad$ learn.
I think the format made the class much more interesting and enjoyable.
I liked it because it mixed things up. I also enjoyed the discussions that they sparked.
I loved the group testing!! The lectures were very exciting and well worth attending. You made the information
interesting by adding humor (and) by telling real stories.
It involved us, and that way I was less stressed and did better in the class overall

*It is quite apparent from the results that the strategies used yielded very positive responses from the students. 
The students were given the opportunity to write additional comments on the evaluation forms about the strategies used. Table 4 below displays examples of written comments from students. The students were asked: "Overall, how did these approaches compare to individual testing and a "straight lecture from the podium" approach.

\section{Discussion}

This study employed the use of four teaching strategies designed to promote active learning and enhance student satisfaction with the course in two adolescent development classes, one day and one evening. The overall results were very positive with the great majority of students in both classes affirming their appreciation of the approaches. Grades earned in the course were not a focus of the study, however, it should be noted that the average grade in each of the classes was a "B" and there were no failures in either of the classes. No comparison was done with classes not using these techniques although future research could consider this comparison. The results support the notion that students preferred the use of a variety of active strategies when compared to more passive learning methods. Student satisfaction with the course taught with these strategies is apparent. There is evidence that learning took place according to the self-report data from the students as well as the overall grades earned by the students in the courses. Nearly all the students in the study preferred the use of group or partner tests reporting lessened anxiety and more comfort, similar to the findings of Zimbardo et al. (2003). This test-taking format also provided an additional venue for discussions regarding the materials, thus creating another method of retrieval and reuse, which is valuable for transfer of learning over the long term. It also functioned well as a cooperative learning activity and thus serves to add support to the body of research in cooperative learning. These activities are known to be effective; yet, they are uncommonly used according to a national survey conducted by Thompson and Vermette (2002, as cited in Thompson et al, 2004).

This study is not without limitations. The class sizes were relatively small ( $25-27$ students). Also, the participants were all in attendance at the same small private college, which limits the generalizability of results. In addition, there was only one male participant. This raises the question of whether the positive ratings would remain the same if the participants were both male and female.

What has not been investigated here is the measure of long-term transfer of learning and ability to use the information gained beyond the end of the course that is so vital to our students. This issue offers perhaps an even more challenging quest for us as academic researchers. If these more active methods do, in fact, aid in long-term transfer, then evidence would likely be found "in the field"; in field placements and internships, as well as in the work place. Future research aimed at measures of performance in either or both of these areas may give us further evidence of the long-term transfer of learning.

This study has added to the body of evidence with regard to the usefulness and appeal of certain active learning and collaborative testing strategies. The information is based on anonymous student preference evaluations with both day and evening students.

\section{REFERENCES}

1. Connor-Greene, P.A. (2000). "Assessing and promoting student learning: Blurring the line between teaching and testing". Teaching of Psychology, 27, 84-88.

2. Fontes, L. \& Piercy, F. (2000). "Engaging students in qualitative research through experiential class activities". Teaching of Psychology, 27, 174-179.

3. Halpern, D. F., \& Hakel, M.D. (2003). "Applying the science of learning to the university and beyond: Teaching for long-term retention and transfer". Change, 35-4, 37-41.

4. Halpern, D. F. (2004). "Applying the research and theory of cognitive psychology to teaching and learning: The least you need to know". Newsletter of the Society for the Teaching of Psychology, spring, p.4.

5. Meyers, C. \& Jones, T.B. (1993). Promoting Active Learning: Strategies for the College Classroom. San Francisco, California: Jossey-Bass Inc. 
6. $\quad$ Pascarella, E.T. (2004). "First generation college students: Additional evidence on college experiences and outcomes". The Journal of Higher Education, 75, 249-284.

7. Smith, D. (2003). "Team testing boosts test scores, study finds". Monitor on Psychology, 34, 18.

8. Springer, L., Stanne, M.E. \& Donovan, S.S. (1999). "Effects of small-group learning on undergraduates in science, mathematics, engineering, and technology: A meta-analysis". Review of Educational Research, 69, $21-51$.

9. Thompson, W.B., Vernette, P.J \& Wisniewski, S. A. (2004). "Ten cooperative learning activities for the cognitive psychology course". Teaching of Psychology, 31, $134-136$.

10. Zimbardo, P.G., Butler, L.D. \& Wolfe, V.A. (2003). "Cooperative college examinations: More gain, less pain when students share information and grades". Journal of Experimental Education, 71, 101-125.

\section{APPENDIX A}

Interview Questions

Demographic Information

First Name

Age

Sex

Grade

Type of School

Public

Parochial

Private

\section{Family Information}

Who lives in your home?

What number child are you? Ex. Oldest, middle, youngest.

Do you have step parents?

Describe the relationship you have with your mother... with your father

...with your stepmother

...with your stepfather

....with your brother

...with your sister

...with your grandparents

What kind of responsibilities do you have at home?

What is your favorite thing to do with your family?

How is discipline handled in your family?

Do you and your family go to Church or Temple?

\section{School Information}

What do you like best about your school?

What do you dislike the most about your school?

Describe your school friends.

In your opinion, how prevalent is alcohol use in your school?

Drug use?

Describe the activities you are involved with in school.

What kind of grades do you earn in school?

How much time do you spend doing homework each day?

Do you have a job?

yes

no

If so, how many hours a week do you work? 


\section{Other Questions}

Describe your best friend.

Do you have a boyfriend/girlfriend?

What do you like to do on the weekends?

If you had a really serious problem, with whom would you discuss it?

Whom do you admire the most? Why?

What is the most difficult thing you have ever dealt with so far in your life?

If you could change one thing in your life right now, what would it be?

Describe one fear that you have.

At what age do you believe it is appropriate for girls to have sex for the first time? Boys?

How do you feel about having completed this interview?

\section{APPENDIX B}

The following evaluation is being requested in order to provide me with feedback about four learning and testing approaches that I have utilized in this course. I would very much like your input about them. Your responses will be anonymous and will in no way impact your grade for this course. I simply would like your feedback.

1. You have had the opportunity to take tests in a group/partner format. Please rate your experience with this format.
a. liked it very much
b. liked it
c. liked it a little
d. did not like it
e. did not like it at all

Please write additional comments about group/partner testing below:

2. You conducted a face-to-face interview with an adolescent. Please indicate your opinion about that experience below.
a. liked it very much
b. liked it
c. liked it a little
d. did not like it
e. did not like it at all

Please write additional comments about the interview below:

3. You conducted a naturalistic observation of an adolescent couple or group. Please rate that experience below.
a. liked it very much
b. liked it
c. liked it a little
d. did not like it
e. did not like it at all

Please write additional comments about the observation below:

4. Please state your opinion of the Power Point Presentations and handouts.
a. liked them very much
b. liked them
c. liked them a little d. did not like them e. did not like them it at all 
Please write additional comments about the PowerPoint and handouts below.

Overall, how did these approaches compare to individual testing and a "straight lecture from the podium" approach.

\section{APPENDIX C}

The students were given the following directives.

\section{Naturalistic Observation}

You will be conducting a naturalistic field observation. This means that you will observe the adolescents while remaining an unobtrusive part of the surrounding environment. For example, if you are observing a group of adolescents at the food court in the Mall, you can simply be another customer eating at another table - you blend in unnoticed. You may not be an adult sitting in the back of a classroom of middle school or high school students - you would not blend in and your presence will impact on the adolescents' behaviors. With these guidelines in mind, please complete the following assignment.

Observe an adolescent or group of adolescents in any environment. (Spend approximately 20 minutes doing the observation). Describe what you see in terms of appearance and behaviors and then interpret your observation. Include a description of the adolescent, how physically attractive is the person(s) how he or she (or they are) is dressed, level of cleanliness, hairstyle, etc. Estimate his or her age. Describe the behavior you see (what is she or he doing). If observing a group, describe each person and then include observed interactions among the group. Who is the leader? What evidence is there to support your assumption? Who are the followers? How are they different from the leader? How are they similar? Describe the self-esteem of the people in the group (or individual)? What evidence is there to support your estimation of self-esteem?

Interpret your behavioral observation. For example, what "group" do you think the adolescent belongs to as observed by his or her dress, hairstyle, body piercing, tattoos, speech patterns etc. Relate what you observed and interpreted to what you have read or learned in class.

Type (double-spaced) using a 12 point font, a one and a half to two page (three pages maximum please) paper describing the observation and including the answers to the questions I have raised for you in the above paragraphs.

Enjoy! 
NOTES 